\title{
Validation of Control of Allergic Rhinitis and Asthma Test for Children (CARATKids) - a prospective multicenter study
}

Daniela V. B. R. Linhares ${ }^{1}$, João Almeida L. da Fonseca ${ }^{1,2,3}$, Luís Miguel Borrego ${ }^{4,5}$, Águeda Matos ${ }^{6}$, Ana Margarida Pereira ${ }^{1,2,3,7}$, Ana Sá-Sousa ${ }^{1}, \hat{A}_{n g e l a ~ G a s p a r}{ }^{4}$, Cândida Mendes $^{8}$, Carla Moreira $^{9}$, Eva Gomes $^{3,10}$, Filomena F. Rebelo ${ }^{11}$, José Carlos Cidrais Rodrigues ${ }^{12}$, José Manuel Onofre ${ }^{13}$, Luís Filipe Azevedo ${ }^{1}$, Maria Alfaro ${ }^{14}$, Maria José Calix ${ }^{15}$, Rita Amaral ${ }^{1}$, Rodrigo Rodrigues-Alves ${ }^{16}$, Jaime Correia de Sousa ${ }^{17,18}$ \& Mário Morais-Almeida ${ }^{1,4}$, for the CARATKids study group

${ }^{1}$ CINTESIS - Faculty of Medicine of University of Porto, Porto, Portugal; ${ }^{2}$ Immunoallergy Department, CUF Porto Institute, Porto, Portugal; ${ }^{3}$ Immunoallergy Department, CUF Porto Hospital, Porto, Portugal; ${ }^{4}$ Immunoallergy Department, CUF Descobertas Hospital, Lisbon, Portugal; ${ }^{5}$ Department of Immunology, Faculty of Medical Sciences, NOVA, CEDOC, Lisbon, Portugal; ${ }^{6}$ Pediatric Department, Guimarães Hospital, Guimarães, Portugal; ${ }^{7}$ Immunoallergy Department, Centro Hospitalar S. João, Porto, Portugal; ${ }^{8}$ Pediatric Department, Vila Franca de Xira Hospital, Vila Franca de Xira, Portugal; ${ }^{9}$ Pediatric Department, Braga Hospital, Braga, Portugal; ${ }^{10}$ Immunoallergy Department, Centro Hospitalar do Porto, Porto, Portugal; ${ }^{11}$ Pediatric Department, Centro Hospitalar Oeste Norte, Caldas da Rainha, Portugal; ${ }^{12}$ Pediatric Department, Hospital Pedro Hispano, Matosinhos, Portugal; ${ }^{13}$ Pediatric Department, Santarém Hospital, Santarém, Portugal; ${ }^{14}$ Pediatric Department, Faro Hospital, Faro, Portugal; ${ }^{15}$ Pediatric Department, Hospital São Teotónio, Viseu, Portugal; ${ }^{16}$ Immunoallergy Department, Hospital Divino Espírito Santo, Ponta Delgada, Açores, Portugal; ${ }^{17}$ Life and Health Sciences Research Institute (ICVS), School of Health Sciences, University of Minho, Braga, Portugal; ${ }^{18}$ ICVS/3B's, PT Government Associate Laboratory, Braga/Guimarães, Braga, Portugal

To cite this article: Linhares DVBR, da Fonseca JAL, Borrego LM, Matos Á, Pereira AM, Sá-Sousa A, Gaspar Â, Mendes C, Moreira C, Gomes E, Rebelo FF, Cidrais Rodrigues JC, Onofre JM, Azevedo LF, Alfaro M, Calix MJ, Amaral R, Rodrigues-Alves R, Correia de Sousa J, Morais-Almeida M, for the CARATKids study group. Validation of Control of Allergic Rhinitis and Asthma Test for Children (CARATKids) - a prospective multicenter study. Pediatr Allergy Immunol $2014:$ 25: 173-179.

\section{Keywords}

asthma; allergic rhinitis; child; questionnaires; patient-reported outcomes

\section{Correspondence \\ João Almeida Lopes da Fonseca, Faculty of Medicine of University of Porto, Alameda Hernâni Monteiro, 4200-319 Porto, Portugal. \\ Tel.: +351225513622 \\ Fax: +351225513623 \\ E-mail: fonseca.ja@gmail.com}

Accepted for publication 14 February 2014

DOI:10.1111/pai.12218

\begin{abstract}
Background: Control of Allergic Rhinitis and Asthma Test for Children (CARATKids) is the first questionnaire that assesses simultaneously allergic rhinitis and asthma control in children. It was recently developed, but redundancy of questions and its psychometric properties were not assessed. This study aimed to (i) establish the final version of the CARATKids questionnaire and (ii) evaluate its reliability, responsiveness, cross-sectional validity, and longitudinal validity.

Methods: A prospective observational study was conducted in 11 Portuguese centers. During two visits separated by $6 \mathrm{wk}$, CARATKids, visual analog scale scales and childhood asthma control test were completed, and participant's asthma and rhinitis were evaluated by his/her physician without knowing the questionnaires' results. Datadriven item reduction was conducted, and internal consistency, responsiveness analysis, and associations with external measures of disease status were assessed.

Results: Of the 113 children included, 101 completed both visits. After item reduction, the final version of the questionnaire has 13 items, eight to be answered by the child and five by the caregiver. Its Cronbach's alpha was 0.80, the Guyatt's responsiveness index was -1.51 , and a significant $(\mathrm{p}<0.001)$ within-patient change of CARATKids score in clinical unstable patients was observed. Regarding cross-sectional validity, correlation coefficients of CARATKids with the external measures of control were between 0.45 and -0.69 and met the a priori predictions. In the longitudinal validity assessment, the correlation coefficients between the score changes of CARATKids and those of external measures of control ranged from 0.34 to 0.46 .

Conclusion: CARATKids showed adequate psychometric properties and is ready to be used in clinical practice.
\end{abstract}

Asthma and allergic rhinitis (ARA) are chronic inflammatory diseases of the airways that often coexist in children (1). Rhinitis increases the risk of asthma and impairs its control
(2-4). When non-controlled, these conditions are responsible for a significant decrease in patient's quality of life (1). Currently, clinical asthma control is defined as the frequency 
and intensity of symptoms and functional limitations that a patient experiences or has recently experienced as a consequence of the disease and includes day and night symptoms, use of reliever therapy, activity limitations, and lung function measurements (5). Rhinitis control has never been formally defined. Nevertheless, Demoly et al. (6) recently argued for the use of the concept of rhinitis control as a way to improve clinical decisions.

CARAT10 was the first tool that was developed and validated to assess ARA control in adults (age $\geq 18 \mathrm{yr}$ ) (6-8). In children, until recently, there were several available tools evaluating asthma control, but as far as we know, there was no tool assessing the control of rhinitis or ARA. Control of Allergic Rhinitis and Asthma Test for Children (CARATKids) was developed to evaluate ARA control in children with 6-12 yr old. This initial version of CARATKids has 17-item and was developed from CARAT and other pediatric questionnaires, in a two-phase study with consensus meetings between specialized physicians on the area, and cognitive interviews of children and their caregivers (7); it uses a dichotomic scale (Yes/No answers), with easily understandable questions and images for children.

This study aims to (i) define the final version of the CARATKids questionnaire (item reduction and content structure and layout improvement) and (ii) to evaluate its reliability, responsiveness, and cross-sectional and longitudinal validity.

\section{Methods}

\section{Study design and setting}

A multicentric prospective observational study was conducted in eleven centers located in five of the seven Portuguese regions. Allergists and pediatricians were invited to participate, and one to five physicians at each center joined the study. This study comprised two visits, 3-6 wk apart, and was conducted between July 2012 and February 2013.

\section{Participants}

All patients between 6 and $12 \mathrm{yr}$ old, with a previous medical diagnosis of asthma and allergic rhinitis, followed at the participating centers, for at least three months, were eligible. Children with other respiratory or chronic diseases that could interfere with the study measurements, as well as parents and children unable to fill the questionnaire, were excluded. The study was approved by the Hospital CUF Descobertas' ethics committee, and each patient's parents gave their written informed consent.

\section{Data Collection}

Questionnaires were completed at each visit by children and their caregivers, namely CARATKids, childhood Asthma Control Test (cACT), and visual analog scale (VAS) of rhinitis and asthma control. CARATKids' initial version has 17 questions, with two answer options - 'Yes', scored as $1=$ no control (symptom/item present); and 'No', scored as
$0=$ control (symptom/item not present). The attending physician performed a medical evaluation and filled out VAS of rhinitis and asthma control. Physicians were blinded to patient/ caregiver's questionnaire responses. Characteristics of the questionnaire according to patient-reported outcomes $\mathrm{Ga}^{2}$ len recommendations are presented on Table S1 (8).

\section{Data Analysis}

Sample size was established using COSMIN recommendations (9). To assess over 100 participants, with an attrition rate of $10 \%, 115$ patients were planned to be included. Sample characteristics were described by standard descriptive statistics. The variables' distribution was plotted to visually assess the distribution, and parametric and nonparametric tests were used as appropriate.

The physicians' VAS assessing asthma or rhinitis control were categorized as dichotomous variables, classifying the patient as controlled or uncontrolled. Disease control was defined as a VAS measurement to be greater than six out of a scale ranging from 0 (bad) to 10 (good), according to previous reports (10). This was applied for the control of allergic rhinitis as well as asthma control. Asthma control was also classified according to the Global Initiative for Asthma (GINA) guidelines (5) and to cACT, with controlled asthma defined as a score of 19 or less (11). A patient was considered controlled when both asthma and rhinitis were controlled, taking into account the GINA classification for asthma and physician VAS classification for rhinitis. The rhinitis severity was classified according to Allergic Rhinitis and its Impact on Asthma (ARIA) recommendations (12). Patients who were graded between 5.0 and 6.0 in the second visit's control variation VAS of both asthma and rhinitis were considered to be clinically stable.

All answers were analyzed and response rates computed. Results from physician assessment measures and children/ caregiver's answers in each visit were pooled and plotted against CARATKids scores and factors.

\section{Item reduction}

Item reduction was based on statistical criteria and on a consensus meeting with an expert panel held in May 2013. Stepwise logistic regression was performed to reduce the 17-item working questionnaire. Exploratory factor analysis and internal consistency analysis were also performed and taken into account for the item reduction. An item was considered redundant, and it was discarded, if one of the following occurred: a) responses over $95 \%$ in a single category of a variable; b) a p-value of less than 0.10 in logistic regression analysis; c) considerable cross-loading $(>0.300$ in more than one factor) or low item-total correlation $(<0.400)$ or increased Cronbach's alpha if the item was deleted.

\section{Evaluation of CARATKids}

Control of Allergic Rhinitis and Asthma Test for Children measurement properties were assessed according to the 
COSMIN checklist (9): (i) reliability (internal consistency, using Cronbach's $\alpha$; test-retest reliability, using intraclass correlation coefficient (ICC)), (ii) responsiveness (withinpatient change in CARATKids score; Guyatt's responsiveness index (GRI)), (iii) discriminative properties and validity - (iii.a) concurrent validity (physician assessment, self-assessment, and cACT); (iii.b) longitudinal validity (physician assessment, selfassessment, and cACT); and (iii.c) hypothesis testing, with $a$ priori predictions for concurrent validity for the correlation defined as: (i) $0.5-0.7$ with cACT; (ii) $0.4-0.7$ with the symptoms VAS; (iii) $0.4-0.6$ with the physician's assessment). Confidence intervals (CI) for correlation coefficients were calculated using bootstrap methods. Lower and upper limits of the $95 \% \mathrm{CI}$ corresponded to the percentiles 2.5 and 97.5 of the distribution of the sample statistics after thousand replicates (random samples with replacement of the same size as the original sample) for each estimate.

The statistical analysis was carried out using SPPS 21.0. (SPSS Inc., Chicago, IL, USA). The level of significance was set at $\mathrm{p}<0.05$.

\section{Results}

The 113 patients included were assessed by 23 physicians at 11 outpatients' clinics. Twelve patients $(10.6 \%)$ did not attend the second visit. The general characteristics of patients are summarized in Table 1. Of the 103 with complete data on allergy,

Table 1 Characteristics of participants

\begin{tabular}{|c|c|c|}
\hline & $\begin{array}{l}\text { Visit } 1 \\
n=113\end{array}$ & $\begin{array}{l}\text { Visit } 2 \\
n=101\end{array}$ \\
\hline Age mean (s.d.) yr & $8.75(1.86)$ & $8.84(1.82)$ \\
\hline \multicolumn{3}{|l|}{ Gender $\mathrm{n}(\%)$} \\
\hline Male & $69(61.1)$ & $64(63.4)$ \\
\hline Female & $44(38.9)$ & $37(36.6)$ \\
\hline cACT score (p25-p75) & $23(19-25)$ & $24(21.3-26)$ \\
\hline \multicolumn{3}{|l|}{ Physician assessment } \\
\hline \multicolumn{3}{|c|}{ Asthma Control - GINA n (\%) } \\
\hline Uncontrolled & $12(10.6)$ & $4(3.5)$ \\
\hline Partly controlled & $36(31.9)$ & $18(15.9)$ \\
\hline Controlled & $46(40.7)$ & $65(57.5)$ \\
\hline \multicolumn{3}{|l|}{ Rhinitis - ARIA n (\%) } \\
\hline Intermittent & $43(38.1)$ & $50(44.2)$ \\
\hline Persistent & $66(58.4)$ & $49(43.4)$ \\
\hline Mild & $73(64.6)$ & $82(72.6)$ \\
\hline Moderate/Severe & $37(32.7)$ & 19 (16.8) \\
\hline \multicolumn{3}{|c|}{ VAS control median (p25-p75) } \\
\hline Asthma & $5(8-9)$ & $9(8-9.5)$ \\
\hline Rhinitis & $6(4-8)$ & $8(6-9)$ \\
\hline \multicolumn{3}{|c|}{ Treatment decision n (\%) } \\
\hline Reduce & $8(7.1)$ & $9(9.1)$ \\
\hline Maintain & $51(45.5)$ & $68(68.7)$ \\
\hline Increase & $53(47.3)$ & $22(22.2)$ \\
\hline
\end{tabular}

CACT, childhood Asthma Control Test; GINA, Global Initiative for Asthma; ARIA, Allergic Rhinitis and its Impact on Asthma; VAS, visual analog scale.
98 were positive to house dust mites and 32 for pollens, mostly grass pollen, and 13 sensitized to cat or dog.

Overall, $0.3 \%$ of all CARATKids questions were not answered. The items with more missing items each with two missings (1.8\%) were 'Wheezing', by both children and parents, 'Rhinorrhoea' and 'Throat symptoms' by children, and 'Nasal Obstruction' and 'Dyspnoea' by parents.

For longitudinal analysis, full data on disease control were available for 80 patients. Twenty-nine patients $(36 \%)$ were classified as having clinically stable asthma and rhinitis. The unstable group included 51 patients, 15 with both unstable asthma and rhinitis, 16 with only unstable rhinitis, and 20 with only unstable asthma.

\section{Item reduction}

Internal consistency was better when questions were answered by the parents and children separately than when answered together. Moreover, the responses of parents and children separately had better correlation coefficients with comparative measures than questions answered by parents and children together (data not shown). The expert panel, held to discuss item selection, decided the questions should be answered by the children and the parents separately (Fig. S1). The item 'Hospitalization' was eliminated, because it had more than 95\% of answers 'No'. Then, using stepwise logistic regression, the items 'Nasal pruritus', 'Throat symptoms', and 'Ocular symptoms' were excluded (Fig. S1). Internal consistency analysis was in agreement with this 13-item version of the questionnaire. Exploratory factor analysis identified four factors and had no contribution to the item reduction. The final questionnaire had 13 questions. Based on the data from internal consistency and logistic regression analysis and the associations with external comparison measures, eight questions are best answered by the children and five by the parents.

\section{Properties and Evaluation of CARATKids}

Control of Allergic Rhinitis and Asthma Test for Children had a median (P25-P75) score of 4 (2-7) in the first visit and of 3 $(1-5)$ in the second one. Nine patients $(8.2 \%)$ in visit 1 and 13 $(15.6 \%)$ in visit 2 had the minimum score of 0 , and $2(1.8 \%)$ in visit 1 and $1(0.9 \%)$ in visit 2 had the maximum score of 13 . The mean (s.d.) score difference between the two visits was of -1.46 (3.34), $p<0.001$. Control of Allergic Rhinitis and Asthma Test for Children scores were significantly different when comparing patients with controlled, uncontrolled, and partly controlled asthma, and when comparing children with mild rhinitis with those with moderate to severe disease $(\mathrm{p}<0.05)$. Scores differed significantly between physician's treatment decision groups (reduction, maintenance, or increase), GINA classification of asthma control, and ARIA classification of severity (Fig. 1 and Table S2). In both visits, significant differences are observed in CARATKids scores between control groups defined by cACT (Fig. 1).

In the internal consistency analysis, the Cronbach's alpha was 0.80 for CARATKids. 

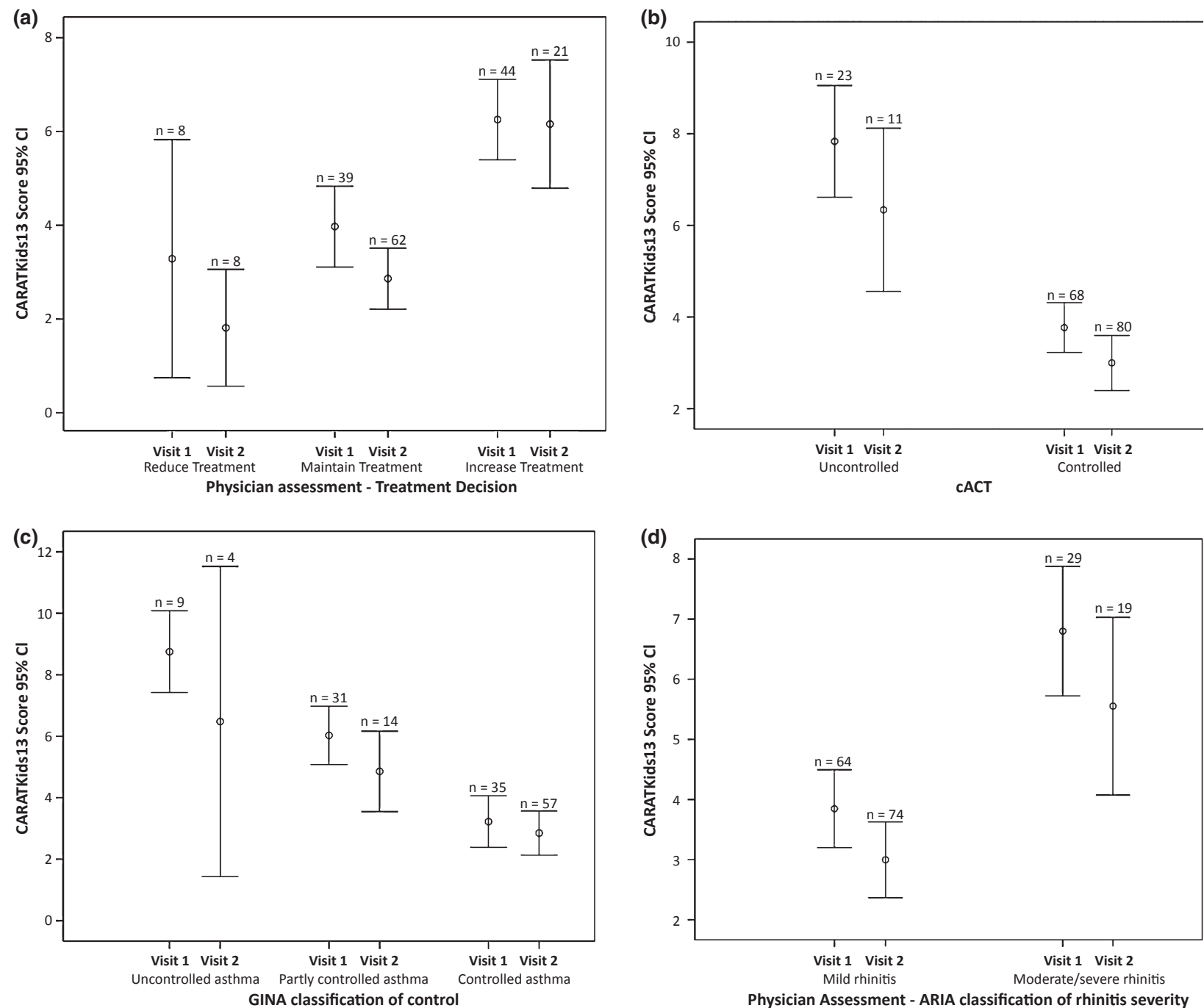

Figure 1 Mean and 95\% confidence intervals of CARATKids scores in both visits 1 and 2 with: (a) physician's decision of treatment reduction, maintenance, or increase; (b) asthma control classified by CACT; (c) GINA classification of asthma control; and (d) ARIA classification of rhinitis severity. CARATKids, Control of Allergic Rhinitis and Asthma Test for Children; CACT, childhood Asthma Control Test; ARIA, Allergic Rhinitis and its Impact on Asthma; GINA, Global Initiative for Asthma.

All correlation coefficients met the a priori predictions (Table 2). Coefficients varied between 0.430 and -0.689 (all $\mathrm{p}<0.001)$. Correlation coefficient of CARATKids scores with GINA classification of asthma control was of -0.60 (95\% CI $-0.728 ;-0.442)$ and of $0.430(0.235 ; 0.584)$ with ARIA classification of rhinitis severity $(\mathrm{p}<0.001)$.

Receiver operating characteristic curves for CARATKids are shown in Fig. 2. The areas under the curve for CARATKids ranged from 0.761 (physician evaluation of rhinitis control) to 0.826 (cACT).

In the test-retest reliability analysis, the ICC was 0.80 in the stable group. When evaluating responsiveness, we observed a significant within-patient change of CARATKids score in clinically unstable patients, not only when both the conditions were unstable (mean (s.d.) change of -3.8 (2.83), p < 0.001) but also when at least one was unstable $(-2.1$ (3.54), $\mathrm{p}<0.001)$. In the stable group, there was a non-significant difference (mean (s.d.) of -0.59 (2.52), $\mathrm{p}=0.23$ ) between CARATKids scores in the two visits. The GRI was of 1.51 in the group with both conditions unstable.

The range of the correlation coefficients between the variation in CARATKids scores and the variation in physician assessment of control using VAS was -0.454 and -0.446 , meeting the a priori prediction (Table 2).

\section{Discussion}

This article describes the clinical evaluation of CARATKids, the first questionnaire developed to concurrently assess asthma and allergic rhinitis control in 6- to 12-yr-old children. A process of item reduction from the initial 17 -item version of CARATKids was performed to reduce redundancy and 
Table 2 Correlation coefficients between CARATKids with external measures of control and of between-visits changes (variation) of CARATKids scores (ACARATKids) and between-visits changes of external measures of control

\begin{tabular}{|c|c|c|c|c|c|}
\hline & \multicolumn{2}{|c|}{ Physician Assessment - VAS/AVAS } & \multicolumn{2}{|c|}{ Children Assessment - VAS/AVAS } & \multirow[b]{2}{*}{ сACT/ $\triangle \mathrm{cACT}$} \\
\hline & Asthma Control & Rhinitis Control & Asthma Control & Rhinitis Control & \\
\hline CARATKids & $-0.548(-0.678 ;-0.371)$ & $-0.499(-0.648 ;-0.308)$ & $0.608(0.439 ; 0.74)$ & $0.446(0.266 ; 0.591)$ & $-0.689(-0.805 ;-0.543)$ \\
\hline$\Delta$ CARATKids & $-0.446(-0.656 ;-0.163)$ & $-0.454(-0.687 ;-0.177)$ & $0.466(0.19 ; 0.687)$ & $0.447(0.172 ; 0.663)$ & $-0.344(-0.633 ;-0.033)$ \\
\hline
\end{tabular}

Data are presented as Spearmen correlation coefficients (95\% CI). CARATKids, Control of Allergic Rhinitis and Asthma Test for Children; VAS, visual analog scale; cACT, childhood Asthma Control Test.
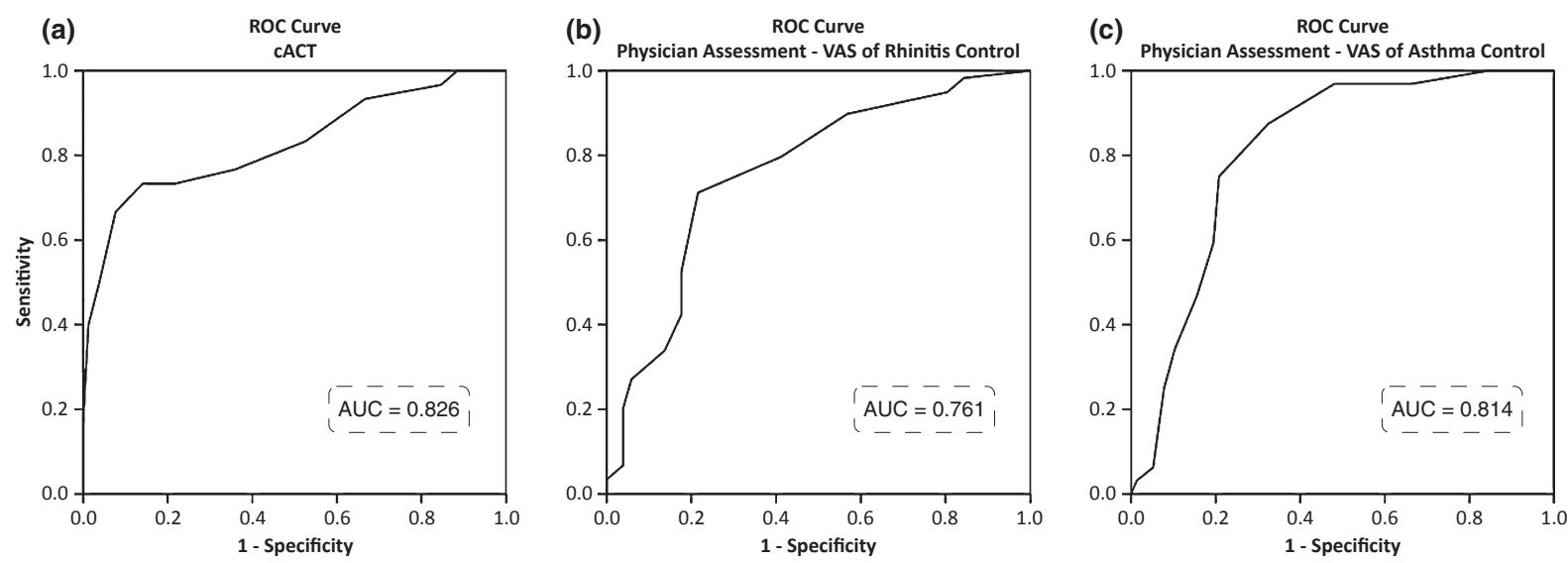

Figure 2 Receiver operating characteristic curves of CARAT10 score against (a) asthma control classified by cACT; physician assessment of (b) rhinitis and (c) asthma control. ROC, receiver operating characteristic; CACT, childhood Asthma Control Test; VAS, visual analog scale; AUC, area under curve.

improve the questionnaire's reliability and validity. The 13-item questionnaire showed to have good discriminative properties.

Of the 13 items, five are to be answered by parents and eight by children (Fig. S1). Although this method of a twofold answer was found to be the most adequate solution, the usability of the questionnaire is somehow reduced by the parent and child response method. However, previous studies on asthma also observed divergence between children and parent-reported variables, with some sets of questions being better answered by each of them $(11,13,14)$. In fact, cACT also has a twofold answer method (11). The questions on sneezing and other nasal symptoms had better results when answered by the children, while parents may be less aware of the frequency of these symptoms. In the cognitive interviews performed in the initial stages of CARATKids development, this lack of concordance was already observed (7).

The internal consistency was satisfactory (15), being similar or better than other questionnaires evaluating asthma control in children, such as cACT (11), Asthma Control Questionnaire (ACQ) in Children (CAN) (16), Test for Respiratory and Asthma Control in Kids (TRACK) (17), ACQ in children (18), or Asthma Quiz (19) (Table 3); however, it was slightly lower than the one in adult's questionnaires, as CARAT (20) and Asthma Control Test (ACT) (21) (Table 3). The areas under the curve were high (0.761-0.826), namely when compared with physician assessment of control and cACT (Fig. 2) assumed as comparators. These are in the same range of those previously observed in studies on adults and are higher than the ones reported for cACT (Table 3 ).

A gold standard for ARA control has not been established yet. Therefore, concurrent validity was assessed using different external measures of control, based on physicians, children, and caregivers' assessments. A priori predictions were met, and all coefficients are in the same range as those observed with other tools to assess control, both in children and adults (Table 3).

In test-retest reliability analysis, CARATKids scores showed an ICC similar or better than those of ACQ in children, TRACK, CAN, ACT, and CARAT (Table 3).

Large responsiveness, greater than 0.8 was observed (22). Moreover, the magnitude of GRI of CARATKids (1.51) was similar to the one of CARAT (1.54).

Regarding longitudinal validity, correlation coefficients were higher than a priori predictions for physician and children VAS of both asthma and rhinitis control (Table 2), but not for $\mathrm{cACT}$. As we could not find longitudinal validity assessment of cACT, it is difficult to interpret the low correlation coefficient we observed between $\triangle$ CARATKids scores and $\triangle \mathrm{cACT}$. This low correlation may be related to differences in sensitivities or responsiveness of the questionnaires. In any case, in both visits, significant differences were observed in CARATKids scores between cACT control groups (Fig. 1). The only control questionnaires for children with published longitudinal validity results are ACQ in 
Table 3 Psychometric properties of control questionnaires for asthma only, and for asthma and allergic rhinitis

\begin{tabular}{|c|c|c|c|c|c|c|}
\hline & $\begin{array}{l}\text { Internal } \\
\text { consistency }\end{array}$ & $\begin{array}{l}\text { Concurrent } \\
\text { validity }\end{array}$ & $\begin{array}{l}\text { ROC curves } \\
\text { (AUC) }\end{array}$ & $\begin{array}{l}\text { Test-retest } \\
\text { ICC }\end{array}$ & Responsiveness & Longitudinal validity \\
\hline \multicolumn{7}{|l|}{ For children } \\
\hline CARATKids & 0.80 & $\begin{aligned} & 0.37-0.73, \text { all } \\
p< & 0.001\end{aligned}$ & $0.76-0.83$ & 0.80 & $\begin{array}{l}\text { Significant within-patient } \\
\text { change }\end{array}$ & $\begin{aligned} & 0.32-0.44, \text { all } \\
p< & 0.05\end{aligned}$ \\
\hline cACT (11) & 0.79 & $\begin{aligned} & 0.47-0.68, \text { all } \\
& <0.001\end{aligned}$ & $0.67-0.71$ & NA & NA & NA \\
\hline ACQ in children $(18,24)$ & 0.75 & $0.52-0.83$ & 0.60 & 0.79 & $\begin{array}{l}\text { Significant within-patient } \\
\text { change }\end{array}$ & $0.66-0.89$ \\
\hline TRACK $(17,25)$ & 0.75 & NA & 0.78 & 0.63 & $\begin{array}{l}\text { Significant within-patient } \\
\text { change }\end{array}$ & NA \\
\hline Asthma Quiz (19) & 0.73 & NA & NA & NA & NA & NA \\
\hline CAN (16) & 0.82 & $-0.18 ;-0.14^{*}$ & $0.73-0.77$ & 0.73 & $\begin{array}{l}\text { Significant within-patient } \\
\text { change }\end{array}$ & $-0.34 ;-0.23^{*}$ \\
\hline \multicolumn{7}{|l|}{ For adults } \\
\hline CARAT $(20,26)$ & 0.85 & $\begin{aligned} & 0.48-0.71, \text { all } \\
p< & 0.001\end{aligned}$ & 0.82 & 0.82 & $\begin{array}{l}\text { Significant within-patient } \\
\text { change }\end{array}$ & $0.31-0.65$ \\
\hline ACT $(21,27)$ & 0.85 & $\begin{array}{rl} & 0.31-0.89, \text { all } \\
p & 0.001\end{array}$ & 0.69 & 0.77 & $\begin{array}{l}\text { Significant within-patient } \\
\text { change }\end{array}$ & $\begin{aligned} & 0.29-0.81, \text { all } \\
p & <0.001\end{aligned}$ \\
\hline ACO $(27,28)$ & NA & $0.19-0.76$ & $0.85-0.90$ & 0.90 & $\begin{array}{l}\text { Significant within-patient } \\
\text { change }\end{array}$ & $0.15-0.73$ \\
\hline
\end{tabular}

When available, data from different sources were used and the higher values on each questionnaire description are presented. CARATKids, Control of Allergic Rhinitis and Asthma Test for Children; CACT, childhood Asthma Control Test; ACQ, Asthma Control Questionnaire; TRACK, Test for Respiratory and Asthma Control in Kids; CAN, Asthma Control Questionnaire for Children; CARAT, Control of Allergic Rhinitis and Asthma Test; ACT, Asthma Control Test; NA, not available.

*Values are for patient and carer's versions, respectively.

children and CAN. The CARATKids longitudinal results are similar to CAN and worse than ACQ in children (Table 3). This may be related to differences in the study design, as ACQ for children was evaluated in a single center, with 3 visits in 4 wk $(0,1$, and $4 \mathrm{wk})$ that included only 35 children (18). Moreover, a guideline-based assessment of asthma control is already available, while the control of rhinitis was defined by physician-derived measures because no gold standard measure is available yet. It is known that there is a bias associated with the physician assessment of control (23), which can partly explain the somewhat lower CARATKids scores. Nevertheless, CARATKids longitudinal validity results were similar to those of control questionnaires in adults and of the CAN questionnaire (Table 3).

This study has several limitations. Interobserver agreement may have been reduced by the high number of observes included, as data were collected by 23 physicians at 11 outpatients' clinics. Nevertheless, this dispersion of data collection may improve the generalizability to the real-world clinical practice. Also, patients were not equally distributed across the range of asthma and rhinitis severity, and for some subgroups, the number of patients was low. This was specially relevant for uncontrolled asthma subgroup for which only 12 patients were accessed. Furthermore, CARATKids was only assessed in children established asthma and allergic rhinitis diagnosis; therefore, its performance in children with only one of the diseases remains unknown.

Minimal important difference and cutoff values are important properties that were not objectives of this study and should be defined in future studies. This would be specially important to use CARATKids in intervention studies. Nevertheless, we conducted exploratory analysis of the cutoff values. We considered one point for each 'Yes' answer and classified the CARATKids scores as controlled $(<4)$, insufficiently controlled $(4,5)$, and uncontrolled $(>5)$. Uncontrolled asthma or rhinitis can be ruled out with a score of three or less and ruled in with a score higher than five with good sensitivity and specificity (Table S3). The clinical usefulness of routine assessment of control in children, using questionnaires, also needs to be assessed in long-term studies.

In conclusion, CARATKids, the first questionnaire assessing allergic rhinitis and asthma control for children 6-12 yr old, showed adequate psychometric properties to be used in clinical practice.

\section{Acknowledgments}

We thank the heads of the departments where the study was conducted, the physicians that participated in the data collection: Alberto Gomes Costa, Cristina Arede, Graça Sampaio, Helder Ferreira, Isabel Andrade, Luís Araújo, Susana Piedade.

\section{Disclosure}

None of the authors received payments or services, either directly or indirectly, from a third party in support of any aspect of this work. 


\section{References}

1. Jeffery PK, Haahtela T. Allergic rhinitis and asthma: inflammation in a one-airway condition. BMC Pulm Med 2006: 6(Suppl 1): S5.

2. Chawes BL, Bonnelykke K, Kreiner-Moller $\mathrm{E}$, Bisgaard H. Children with allergic and nonallergic rhinitis have a similar risk of asthma. J Allergy Clin Immunol 2010: 126: 567-73.e1-8.

3. Ohta K, Bousquet PJ, Aizawa H, et al. Prevalence and impact of rhinitis in asthma. SACRA, a cross-sectional nation-wide study in Japan. Allergy 2011: 66: 1287-95.

4. Morais-Almeida M, Santos N, Pereira AM, et al. Prevalence and classification of rhinitis in preschool children in Portugal: a nationwide study. Allergy 2013: 68: 1278-88.

5. From the Global Strategy for Asthma Management and Prevention, Global Initiative for Asthma (GINA) 2012. Available at: http://www.ginasthma.org/.

6. Demoly P, Calderon M, Casale T, et al. Assessment of disease control in allergic rhinitis. Clin Transl Allergy 2013: 3: 7.

7. Borrego LM, Fonseca JA, Pereira AM, Pinto VR, Linhares D, Morais-Almeida M. Development process and cognitive testing of CARATkids - Control of Allergic Rhinitis and Asthma Test for children. BMC Pediatr 2014: 14: 34.

8. Baiardini I, Bousquet PJ, Brzoza Z, et al. Recommendations for assessing patientreported outcomes and health-related quality of life in clinical trials on allergy: a GA(2)LEN taskforce position paper. Allergy 2010: 65: 290-5.

9. Mokkink LB, Terwee CB, Patrick DL, et al. The COSMIN checklist for assessing the methodological quality of studies on measurement properties of health status measurement instruments: an international Delphi study. Qual Life Res 2010: 19: 539-49.

10. Ohta K, Jean Bousquet P, Akiyama K, et al. Visual analog scale as a predictor of
GINA-defined asthma control. The SACRA study in Japan. J Asthma 2013: 50: 514-21.

11. Liu AH, Zeiger R, Sorkness C, et al. Development and cross-sectional validation of the Childhood Asthma Control Test. J Allergy Clin Immunol 2007: 119: 817-25.

12. Brożek JL, Bousquet J, Baena-Cagnani CE, et al. Allergic Rhinitis and its Impact on Asthma (ARIA) guidelines: 2010 revision. J Allergy Clin Immunol 2010: 126: 466-76.

13. Lara M, Duan N, Sherbourne C, et al. Differences between child and parent reports of symptoms among Latino children with asthma. Pediatrics 1998: 102: E68.

14. Panditi S, Silverman M. Perception of exercise induced asthma by children and their parents. Arch Dis Child 2003: 88: 807-11.

15. Cronbach LJ, Warrington WG. Time-limit tests: estimating their reliability and degree of speeding. Psychometrika 1951: 16: 167-88.

16. Perez-Yarza EG, Badia X, Badiola C, et al. Development and validation of a questionnaire to assess asthma control in pediatrics. Pediatr Pulmonol 2009: 44: 54-63.

17. Chipps B, Zeiger RS, Murphy K, et al. Longitudinal validation of the Test for Respiratory and Asthma Control in Kids in pediatric practices. Pediatrics 2011: 127: e737-47.

18. Juniper EF, Gruffydd-Jones K, Ward S, Svensson K. Asthma Control Questionnaire in children: validation, measurement properties, interpretation. Eur Respir J 2010: 36: 1410-6.

19. Ducharme FM, Davis GM, Noya F, Rich H, Ernst P. The Asthma Quiz for Kidz: a validated tool to appreciate the level of asthma control in children. Can Respir $J$ 2004: 11: 541-6.

20. Fonseca JA, Nogueira-Silva L, MoraisAlmeida M, et al. Validation of a questionnaire (CARAT10) to assess rhinitis and asthma in patients with asthma. Allergy 2010: 65: 1042-8.

21. Schatz M, Sorkness CA, Li JT, et al. Asthma Control Test: reliability, validity, and responsiveness in patients not previously followed by asthma specialists. J Allergy Clin Immunol 2006: 117: 549-56.

22. Lan TY, Deeg DJ, Guralnik JM, Melzer D. Responsiveness of the index of mobility limitation: comparison with gait speed alone in the longitudinal aging study Amsterdam. $J$ Gerontol A Biol Sci Med Sci 2003: 58: 721-7.

23. Juniper EF, Chauhan A, Neville E, et al. Clinicians tend to overestimate improvements in asthma control: an unexpected observation. Prim Care Respir $J$ 2004: 13: 181-4.

24. Nguyen JM, Holbrook JT, Wei CY, Gerald LB, Teague WG, Wise RA. Validation and psychometric properties of the Asthma Control Questionnaire among children. J Allergy Clin Immunol 2014: 133: 91-7.

25. Murphy KR, Zeiger RS, Kosinski M, et al. Test for respiratory and asthma control in kids (TRACK): a caregiver-completed questionnaire for preschool-aged children. J Allergy Clin Immunol 2009: 123: 833-9.e9.

26. Fonseca JA, Nogueira-Silva L, MoraisAlmeida M, et al. Control of Allergic Rhinitis and Asthma Test (CARAT) can be used to assess individual patients over time. Clin Transl Allergy 2012: 2: 16.

27. Jia CE, Zhang HP, Lv Y, et al. The Asthma Control Test and Asthma Control Questionnaire for assessing asthma control: systematic review and meta-analysis. J Allergy Clin Immunol 2013: 131: 695-703.

28. Juniper EF, O'Byrne PM, Guyatt GH, Ferrie PJ, King DR. Development and validation of a questionnaire to measure asthma control. Eur Respir J 1999: 14: 902-7.

\section{Supporting Information}

Additional Supporting Information may be found in the online version of this article:

Table S1. Questionnaire characteristics according to patientreported outcomes' recommendations of $\mathrm{Ga}^{2}$ len (8).
Table S2. CARATKids scores in visit 1 and visit 2 by gender, by GINA and ARIA classifications, and by physician treatment decision.

Table S3. Sensitivity and Specificity for CARATKids' 3 and 5 cutoff values.

Figure S1. CARATKids initial 17 items and final 13-item. 